\title{
High Resolution Imaging of Vadose Zone Transport using Crosswell Radar and Seismic Methods
}

Feb 1, 2002

Ernest L. Majer, Kenneth H. Williams, John E. Peterson, and Thomas M. Daley

Lawrence Berkeley National Laboratory 


\section{INTRODUCTION}

To effectively clean up many contaminated sites there is a need for information on heterogeneities at scales ranging from the centimeter to 10 's of meters, as these features can alter contaminant transport significantly. At the Department of Energy's Hanford, Washington site, heterogeneities of interest can range from localized phenomena such as silt or gravel lenses, fractures or clastic dikes, to large-scale lithologic discontinuities. In the vadose zone it is critical to understand the parameters controlling flow. These features have been suspected of leading to funneling and fingering, additional physical mechanisms that could alter and possibly accelerate the transport of contaminants to underlying groundwater. For example, it has been observed from the studies to date that over relatively short distances there are heterogeneities in the physical structure of the porous medium and structural differences between repacked soil cores and the field site from which the materials initially came(Raymond and Shdo, 1966). Analysis of cores taken from the vadose zone (i.e., soil surface to water table) has been useful in identifying localized zones of contamination. Unfortunately, these analyses are sparse (limited to a few boreholes) and extremely expensive. The high levels of radioactivity at many of the contaminated sites increase drilling and sample costs and analysis time. Cost of drilling and core analysis for the SX tank farm has exceeded $\$ 1 \mathrm{M}$ per borehole (50 $\mathrm{m}$ deep) for sampling. The inability to track highly mobile species through the vadose zone highlights an important need, the need for methods to describe the complete vadose zone plume and to determine processes controlling accelerated contamination of groundwater at Hanford . Crosswell geophysical measurements are one means to provide this information .

The main questions addressed with the crosswell methods in this study are :

- What parts of the vadose zone-groundwater system control flow geometry?

- What physical properties or mechanisms control flow and transport in unconsolidated soils of the vadose zone?

- What is the optimum suite of geophysical field tests to provide information for predicting flow and transport behavior?

- How can the information obtained during site characterization be used for building confidence in predictive numerical models?

Fully developed, application of geophysics should enable location of contaminant distributions. Questions addressed in this study were the sensitivity, resolution, and accuracy of the crosswell methods in order to derive the spatial and temporal distribution of properties controlling transport and contaminant distribution between and away from boreholes and the surface. Implicit in this activity was that geophysical methods will be used to extrapolate and extend measurements made at the point scale to the volumetric scale.

Overall there are two broad hypotheses being addressed in the crosswell geophysical work:

(1) Geophysical methods can identify physical and chemical heterogeneity controlling contaminant transport at a meaningful scale. 
(2) Geophysical methods have the sensitivity to directly or indirectly detect the location of the fluids and/or contaminants at a practical concentration (i.e. subsurface has been altered from its natural state enough to create anomalies that can be detected, i.e., mechanical, electrical, thermal, etc. ).

Examples of specific properties potentially detectable with geophysical methods are:

(1) Change in moisture content in the vadose zone

(2) Degree of continuity/thickness of lithologic units in the vadose zone (Hanford sands, plio-pleistocene caliche, upper Ringold sands, Ringold gravels, etc.)

(3) Location and distribution of heterogeneities within the lithology (sills, clastic dikes, fractures/faults, fracture orientation/density etc.)

(4) Matrix and fracture properties of units (porosity, grain size distribution, moisture distribution, mineral composition, etc.).

(5) Location and extent of contaminant plumes that may have an anomalous chemical or physical signature (precipitation/alteration products, secondary deposition, etc.)

(6) Location of "fast paths" affecting transport (natural and contaminant induced)

\subsection{Approach}

The primary purpose of the crosswell radar and seismic imaging was to provide detailed information on the lithology and structure $(25 \mathrm{~cm}$. or less resolution) as well as provide the same level of detail on the location of the fluid transport during carefully controlled injection experiments. The focus of the measurements was to determine the state variables controlling water movement. (i.e. water content, physical heterogeneities and if possible water potential, chemical concentrations and temperature). It was also desired to determine if the density of the fluid would change the flow behavior. A second major goal was to evaluate these methods and/or modification of the methods to determine their use at tracking leaks from tanks at Hanford during clean up operations.

There have been two major injection events at the site which were monitored with the crosswell radar and seismic methods, one in the spring of 2000 which used Columbia river water and one in the spring of 2001 which used a saline solution (sodium thiosulfate, density of $1.3 \mathrm{~g} / \mathrm{cc}$ ) chased by Columbia river water. In 2000 the injections were in four $4000-\mathrm{L}$ increments of Columbia river water over a 6- week period. In 2001 the injections were five increments of approximately 4000-L of a sodium thiosulfate solution over a five week period, followed by three 4000-L injections of Columbia river water. In 2000 the crosswell data were combined with neutron logging results in steel cased wells. The radar methods were applied in a time lapse sense to determine changes in the moisture content, thus there 
was repeated measurements at the same sites. The crosswell seismic measurements were designed to examine structural and lithologic heterogeneity, thus used only once. We assumed before we applied the seismic measurements that they would be less sensitive to fluid content in the vadose zone, however, as will be seen below the seismic measurements may have high enough frequency content and resolution to provide valuable independent information from the radar measurements.

Figure 1 shows a plan view of the well configuration at the injection test site with the wells marked as " $X$ " as the wells used for the crosswell radar and seismic studies. This site was developed in the 1980's as part of work to understand flow and transport in the vadose zone at Hanford. Thirty two steel cased wells were put in at that time. Additional PVC wells were emplaced for the work described here. These "X" wells were located, based on past experience from prior injection experiments, at the most likely location of flow during the injection experiments. Figure 2 shows a cut away view of the test site and well layout with a conceptual diagram of how flow took place during the last experiments. In the previous experiments an injection well was placed in the center of the well field which was surrounded by the 32 steel cased observation wells. The wells were constructed from three 20 - $\mathrm{ft}$ sections and one 5 - $\mathrm{ft}$ section of 6 in. diameter schedule 40 steel casing.

\footnotetext{
\begin{tabular}{|l|} 
Legend \\
\hline Adv.Tensiometer Nest (Augered) \\
Adv. Tensiom eter Nest (CPT) \\
Cross-Borehole Access \\
ERT Array \\
New Injection Point \\
Subsurface Radiation Zone \\
Split-spocn Cores \\
O Steel-cased Well
\end{tabular}
}

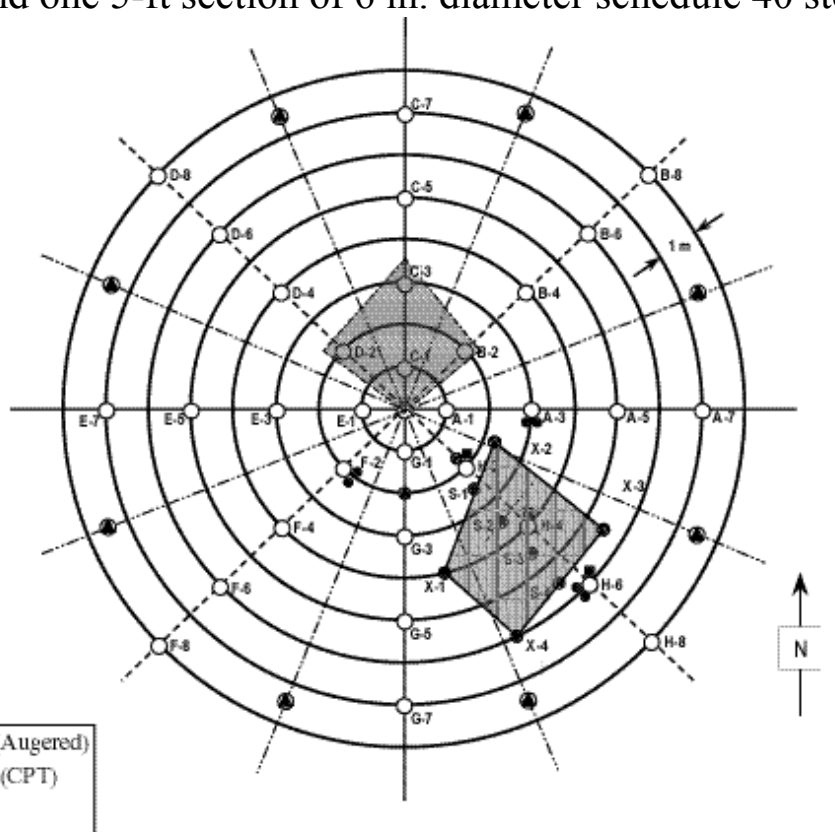

Figure 1 Well array at the Test Site in the 200 East Area at Hanford, Washington. The shaded area beteen $\mathrm{X} 1, \mathrm{X} 2, \mathrm{X} 3$ and $\mathrm{X} 4$ was the target area for the crosswell. The scale is 1 meter between circles. 


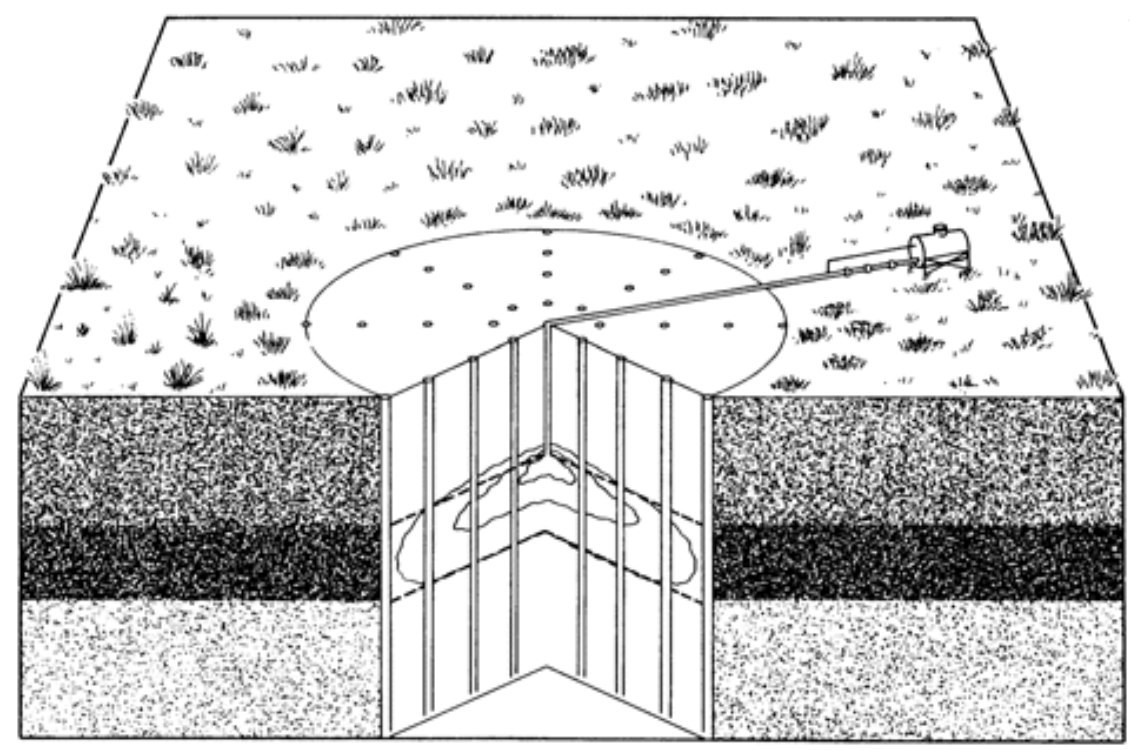

Figure 2 Cut-way conceptual view of test site showing well layout of the 32 steel cased wells.

Samples were collected from the drilling operations, stored in containers and later selected samples were later analyzed for hydraulic properties (Freeman-Pollard et al., 1994 ). In the present case the X wells were PVC cased ( 2 inch I.D.) emplaced with CPT technology.

\section{Data Acquisition}

\section{Crosswell Radar}

The ground penetrating radar (GPR) work consisted of repeated cross well tomographic data sets being collected between the six possible X-well pairs. These include X1-X2, X2-X3, $\mathrm{X} 3-\mathrm{X} 4, \mathrm{X} 1-\mathrm{X} 2, \mathrm{X} 1-\mathrm{X} 3$, and X2-X4. In 2000 a total of four different data sets were collected. One prior to injection as a background data set, two during the injections and one after the injections. In 2001 there were also a total of four data collection visits were made to the site. These include a visit which constituted the base line data set, two days prior to the start of the injection, followed by the monitoring during an initial release of $1900 \mathrm{~L}$ of sodium thiosulfate. The next data set was acquired 30 days later after 19,000 L of sodium thiosulfate had been injected. The last data set was collected 18 days later after $3785 \mathrm{~L}$ of a mixture of tank sluge and river water and $7570 \mathrm{~L}$ of Columbia river water had been injected. All of the radar data were collected using the Sensors \& Software, Inc. PulseEKKO 100 GPR system utilizing the $200 \mathrm{MHz}$ center frequency antennas. The step size for data collection between all well pairs was 0.125 meters in 2000 and 0.25 meters in 2001 . 


\section{Crosswell Seismic}

The crosswell seismic was collected after all of the infiltration tests were completed in both 2000 and 2001. This was due to the fact that the wells used for the crosswell seismic had to be filled with water to enable coupling of the hydrophones and the piezoelectric and mechanical orbital sources. Because we did not know if the wells would leak we did not want to have other water into the formation during the infiltration tests. Until this experiment it has been our experience that it is very difficult to collect high resolution seismic data (in the kilohertz range) in a vadose zone geology. This is due to the fact that partial saturation usually greatly attenuates seismic energy. In 2000 there were four different seismic crosswell sections obtained, three high resolution sections and one long offset section using a distant 6" steel cased hole for a source hole. The three high resolution sections were collected by placing a 24 element hydrophone array in well X4 which was filled with water. A 1.5" diameter by 4" long piezoelectric cylindrical seismic source was then used successively in wells X3, X2, and X1. The long offset section was obtained by leaving the hydrophone array in well X4 (1/2 meter sensor spacing) and placing an DC orbital vibrator source in a well which was also filled with water, approximately 19 meters away from X4. The purpose of this was to see how far seismic energy could be transmitted in the vadose zone. The orbital vibrator is a much stronger source than the piezoelectric source, but puts out lower frequencies, in the 50 to 400 hertz range. In 2001 only the high frequency crosswell seismic data were collected. The piezoelectric data were collected in a tomographic sense at $1 / 4$ meter intervals for both source and receiver. The piezoelectric source put out energy from 1 to 10 kilohertz. Assuming that the resolution is on the order of $1 / 4$ wave length, and the velocities are on the order of 700 meters/sec ( this is what we measured), then we were obtaining possible resolution of $10 \mathrm{~cm}$ for the piezoelectric data and $60 \mathrm{~cm}$ for the orbital source ( assuming 300 hertz for the orbital and 2000 hertz for the piezoelectric source).

\section{Ground Penetrating Radar Results}

Electromagnetic wave slownesses (the reciprocal of velocity) were estimated for this study using the travel times of the propagation waves and a straight ray algebraic reconstruction inversion technique (Peterson et al, 1985). A velocity pixel dimension of 0.25 x 0.25 meters was used for the image inversion. Figure 3 shows the velocities obtained from 
the slowness values between all six wells pairs before the injection in 2000 .

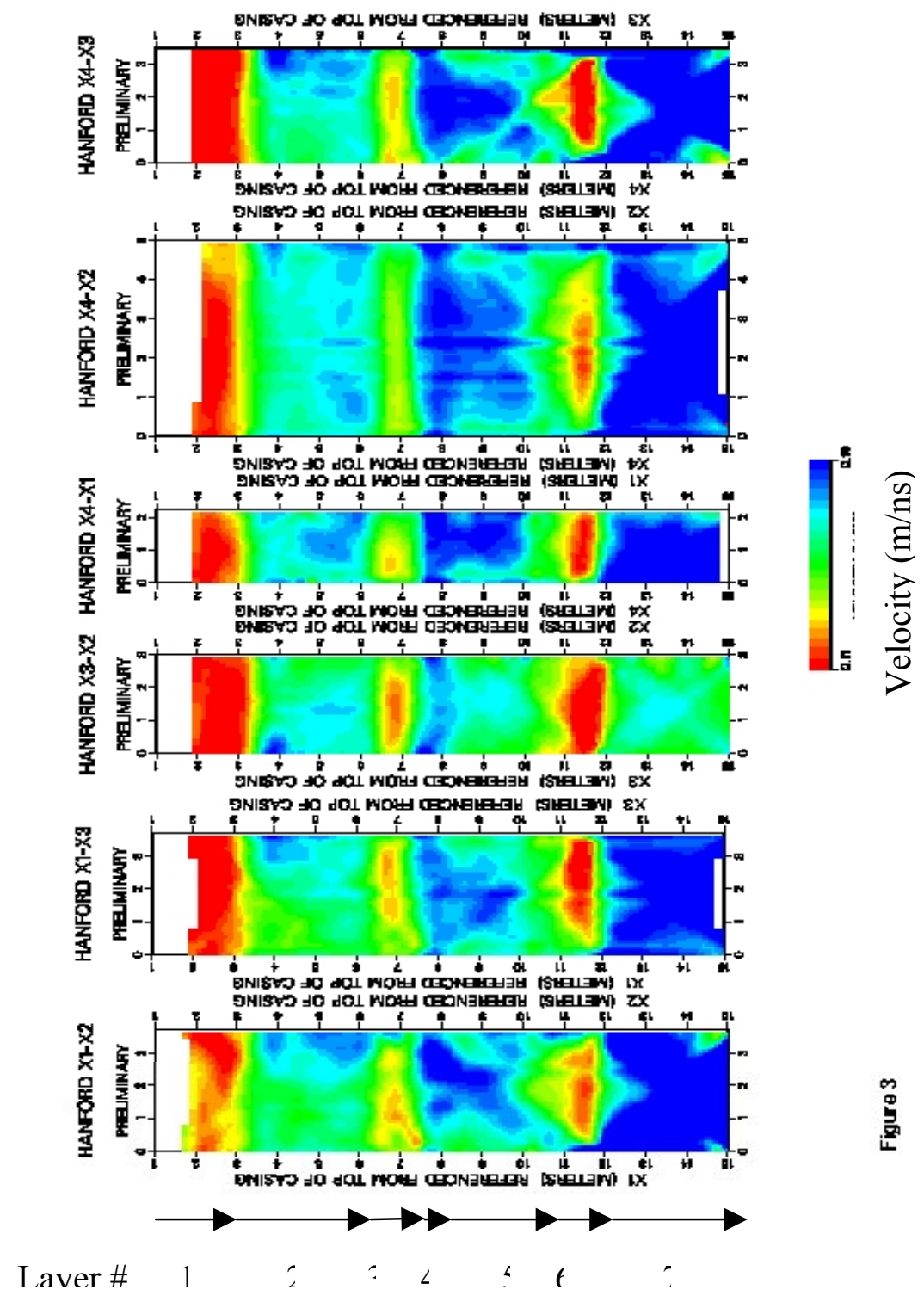

Figure 3 Radar tomographic velocity results from the 2000 pre-injection tests between the different well pairs. Also shown are the layers interpreted from the tomograms.

The pre-injection data set (in addition to the seismic data) was used to delineate the stratigraphic layering. The electromagnetic propagation velocity range observed on the tomograms of approximately $0.11-0.16 \mathrm{~m} / \mathrm{ns}$ is typical for unsaturated, unconsolidated sands.

The variation in radar velocity in unsaturated materials usually indicates variations in moistures and/or texture. The tomograms suggest the presence of six to seven distinct radar 
velocity layers, each continuous across the length of the tomogram and ranging in thickness from 0.25 to 3.5 meters. The layers alternate between higher and lower velocities with the shallowest layer having very low velocities $(<0.11 \mathrm{~m} / \mathrm{ns})$ and extending from the surface to about 3.0 meters below ground surface (BGS). The next deeper layer is of higher velocity $(\sim 0.14 \mathrm{~m} / \mathrm{ns})$ and extends 3.0-3.5 meters below this the first layer to a depth of $\sim 6.5 \mathrm{~m}$. Some lateral velocity inhomogeneity is observed in this layer. The third layer consists of 0.25 to $0.50 \mathrm{~m}$ of low velocity material, which usually indicates higher moisture content, i.e. a fine sand. While this layer is observed to be primarily flat, there appears to be some thickening or splitting of this layer near borehole X1. Another thin layer (Layer 4) 0.25 to $0.50 \mathrm{~m}$ thick consisting of higher velocity material, suggesting a more coarse grain material. This layer has velocities just slightly higher than the layer below it and can be best seen in the X3-X2 tomogram. The next deeper layer (Layer 5) is approximately $3.0 \mathrm{~m}$ thick with similar velocities to those of Layer 2, suggesting that it may be made up of similar material. Layer 6 is similar to Layer 3 in thickness (though slightly thicker at 0.50 to $0.75 \mathrm{~m}$ ) and velocity. Below this is the final (seventh) layer which exhibits the highest velocities $(>0.16 \mathrm{~m} / \mathrm{ns})$. These seven layers extend across the entire set of radar profiles.

The electromagnetic wave velocities $(v)$, obtained from the slowness estimates, can be converted to dielectric constant estimates $(\kappa)$ using: $\kappa=\frac{c^{2}}{v^{2}}$ where $c$ is the velocity of electromagnetic waves through air. Dielectric constants in geologic materials range from approximately 3 to 25 . As the dielectric constant of air is 1 and water is 80 , water content will have the dominant affect on the dielectric constant of an unsaturated material. It is possible to convert the dielectric constant into estimates of water content using a variety of methods. A common method of conversion is through the use of the Topp's curve, which is an empirical relationship between the dielectric constant and water content determined in the laboratory (Topp, et al.,1980). The most direct and precise method is to correlate the field scale dielectric constant estimates obtained from the tomograms near the wells with colocated neutron probe measurements of water content. This was done in the 2000 study with the results for well X3 shown in Figure 4a. Figure 4a shows that there is good correlation in shape between the two curves, thus we used the value of the dielectric constant derived from the velocities by calibrating against the neutron $\log$ results. In general we saw that greater water content correlated with slower radar velocity, as expected. 
HANFCRD $\times 3$

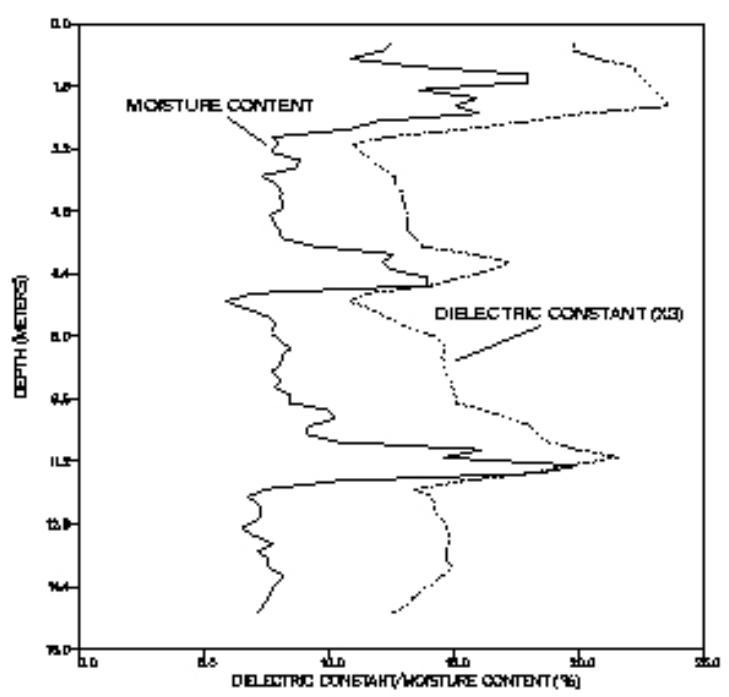

FIGURE 4A

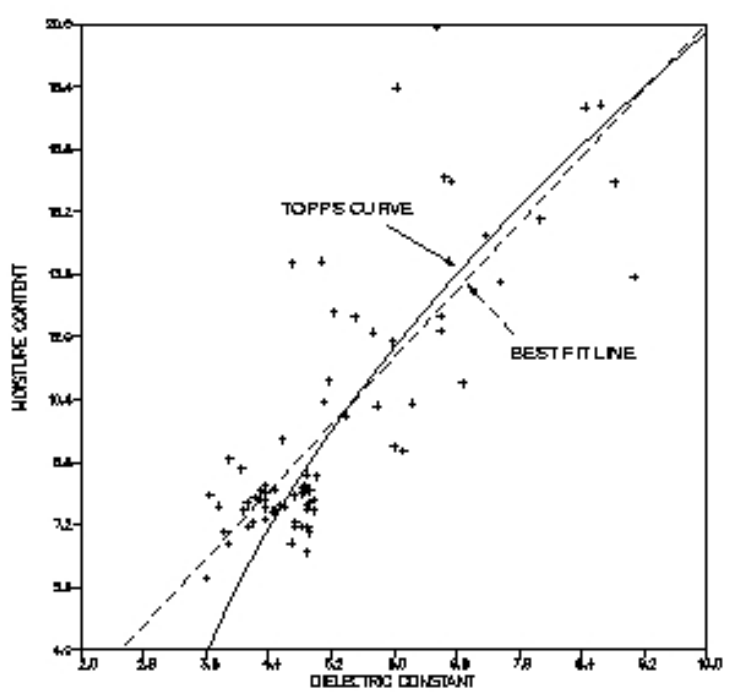

FGURE 4B

Figure 4 The top figure shows the comparison between the dielectric constant estimation from radar data and the moisture content estimation from neutron probe data. The bottom figure shows the best straight line fit of the data compared to Topp's curve. 
As an example Figure 5 shows the comparison of the moisture content derived from the radar data to the moisture content derived from the neutron data prior to the first river water injection. This is assumed to be the initial water content between the wells. This result is for the 2000 data between wells X2 and X3. It should be noted that the neutron data were not taken in these wells but close by (within $1 \mathrm{~m}$ ). The neutron data are extrapolated to derive this image rather than directly sampled as in the case of the radar data. As can be seen there is good spatial correlation between the neutron data and the radar results. Figure 6 shows an example of the differencing the traveling times between the POST1 (acquired one week after the second injection) and the base line measurements (collected in May 2000). After inverting these differences, we obtain an estimate for the change in radar properties. Because the geology remains constant, the observed change in dielectric constant should indicate the change in moisture. These estimates can be converted to change in moisture content using the same sitespecific petrophysical relationship discussed above. Figure 6 shows the changes in moisture content for three of the well pairs associated with POST1. The results indicate that the greatest changes in moisture occur just above the low moisture zone at 6.5 meters depth (Layer 3) and just above the low moisture feature at 10 meters depth (Layer 6). In fact, there appear to be no changes in moisture (or retention in water content) below 10 meters. These data suggest that, at the time of this tomogram (two weeks after Injection 1 and one week after Injection 2), only a small amount of water had flowed (or been retained) into the area sampled by the X4-X3 well pair, which is about 3.5 meters laterally from the injection point. These changes in moisture content can be compared to the neutron probe water content values as illustrated in Figure 7. Although the neutron probe values are not 'differenced' in this figure, a comparison of these values (POST1) with the neutron probe data collected in May 2000 (Figure 5) indicate that moisture content changes detected by the neutron probe correspond to these changes indicated by the tomogram.

POST2 data were acquired during Injection 5 in an attempt to image any change in moisture distribution over the duration of a single injection. Data were acquired only between well pairs X2-X1, the well pair closest to the injection point. Three complete data sets were acquired between these well pairs at discreet intervals after approximately 150, 400 and 900 gallons were released. The data were all subtracted from the baseline measurement acquired the afternoon before the Injection 5 release. After inverting these data, the slownesses were used to estimate changes in water content as described earlier. The change in moisture content, shown in Figure 8, suggests that during the time of active injection the fluid spreads horizontally above the Layer 3 low moisture zone, and that no change in moisture is observed in, or below, this layer during the time of injection.

POST3 data were acquired two weeks after Injection 5, the final injection of fluid. The data were differenced from the May baseline measurements and the resulting changes in moisture content are shown in Figure 9. The regions of increased moisture above Layer 2 and Layer 5 are still observed. However, some moisture increase can now be observed below this level to about 11.5 to 12 meters BGS. 


\section{BASELINE DATA}

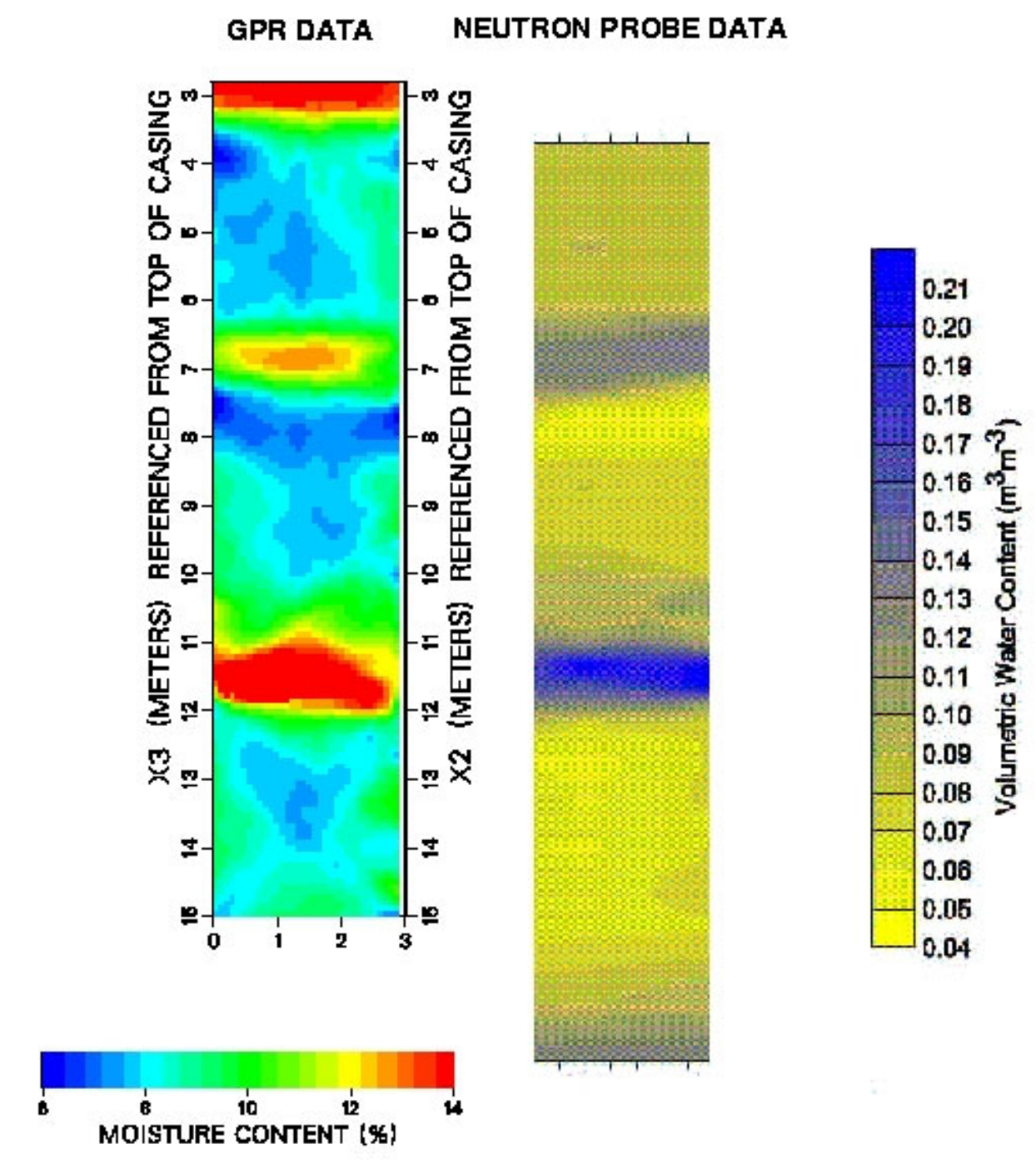

FIGURE 5

Figure 5 Moisture content between wells X2 and X3 from the radar and neutron data 
POST1 MOISTURE CONTENT CHANGES

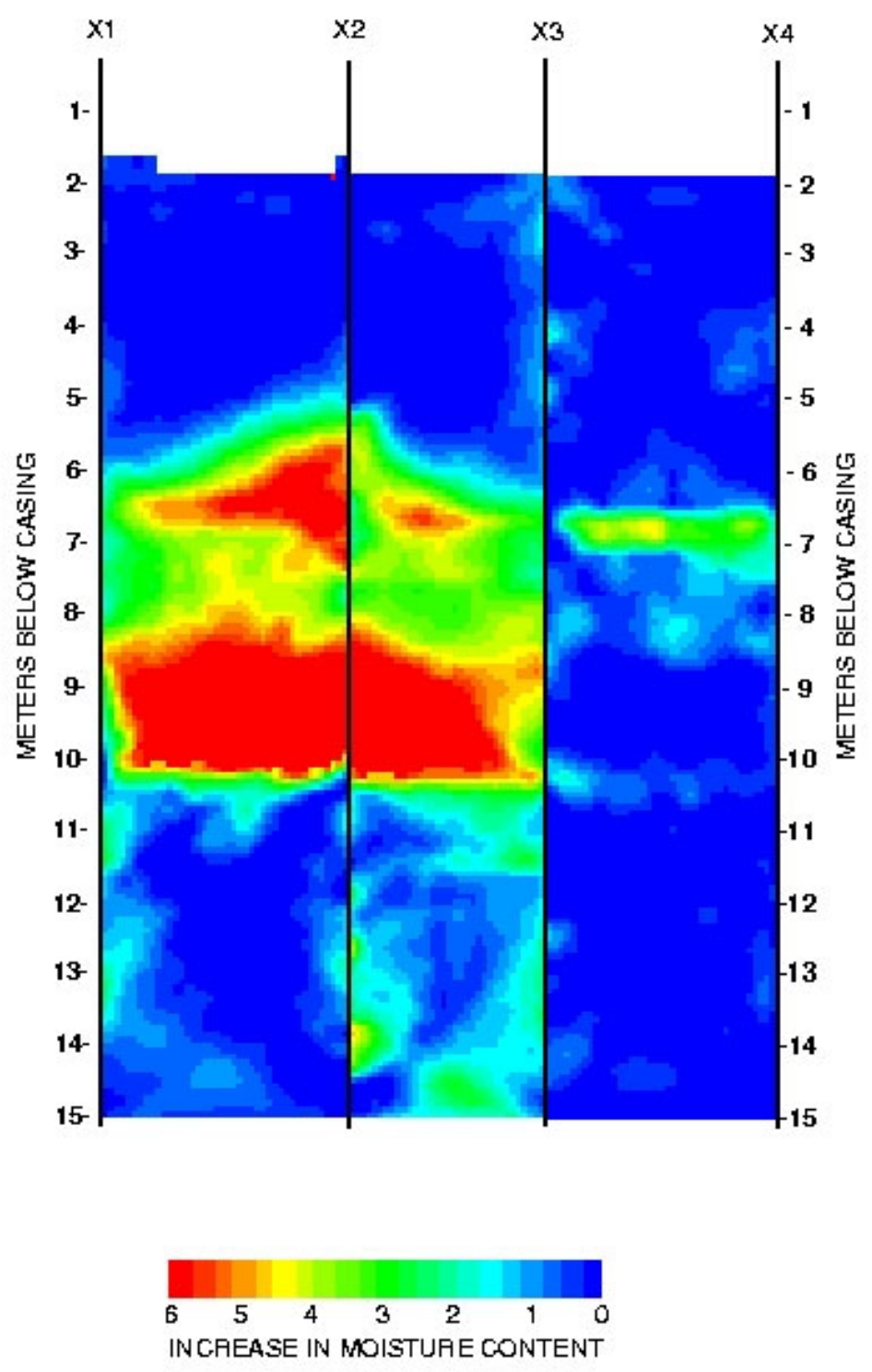

FIGURE 6

Figure 6 Changes in water content after the first water injection in 2000. 


\section{POST INJECTION 2}

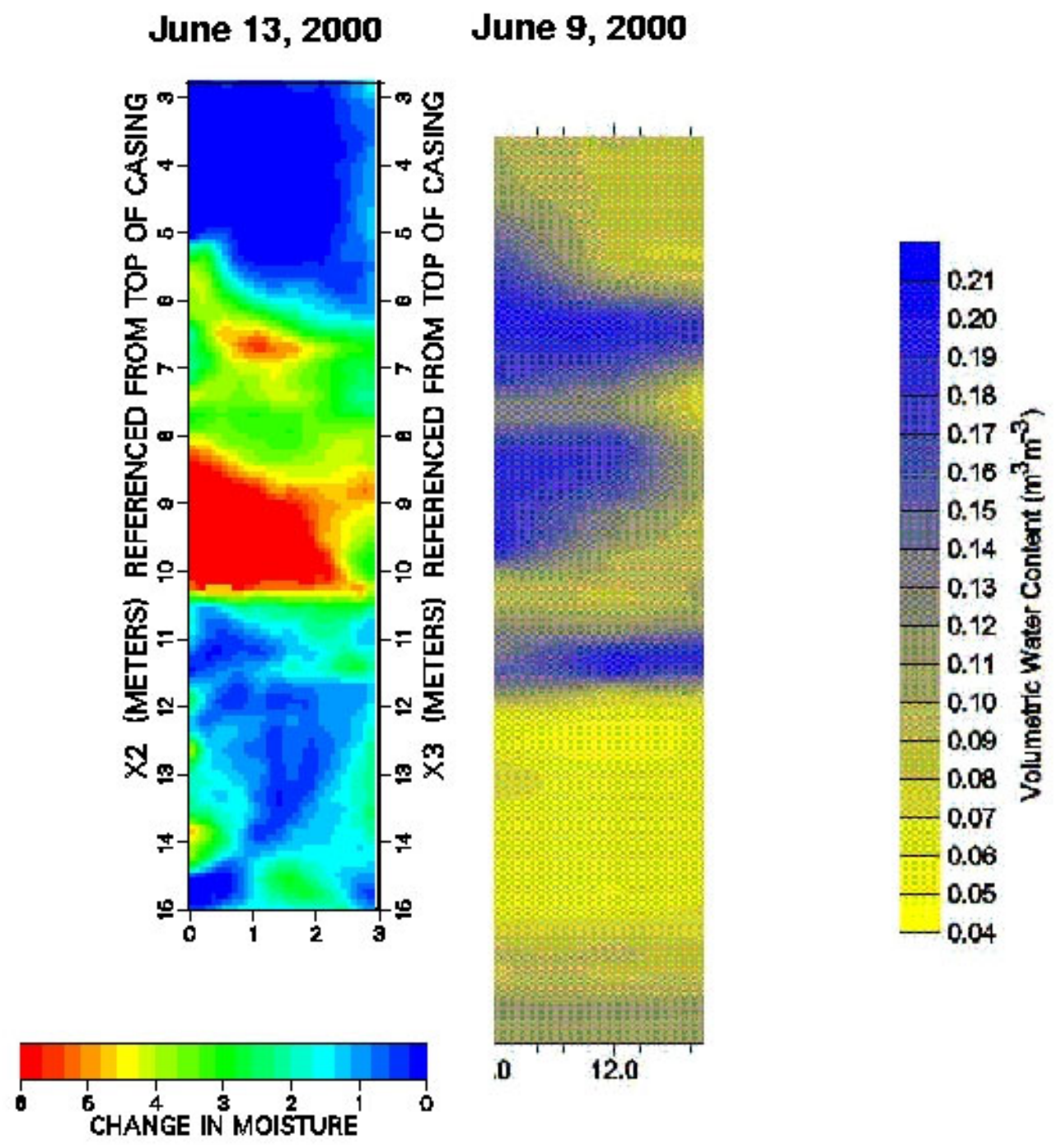

FIGURE 7

Figure 7 Left: Changes in moisture content after the second injection in 2000.

Right: Volumetric water content measured after injection by neutron logging (compare to Fig 5 for changes. 


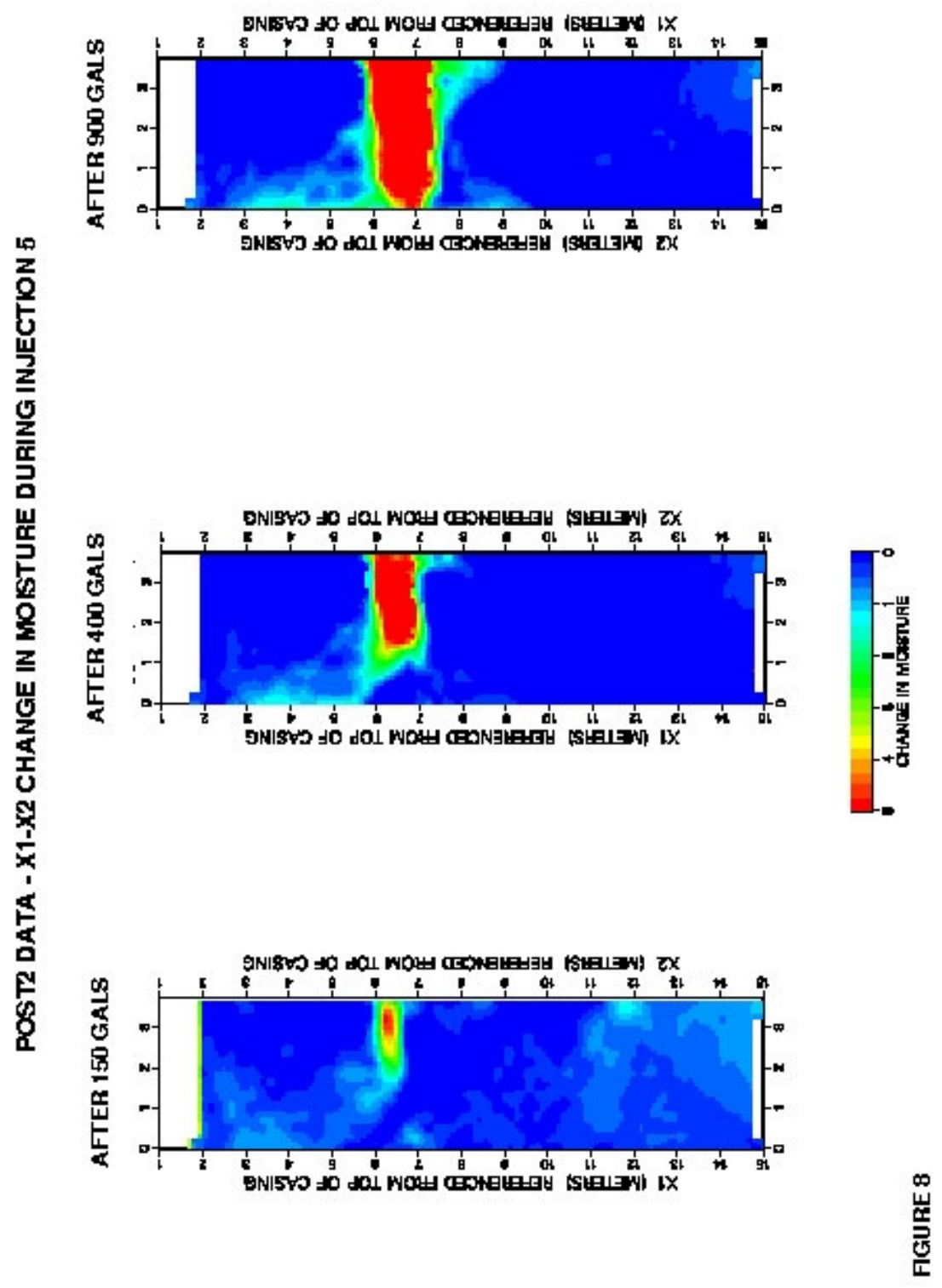

Figure 8 Change in moisture content as measured by radar tomography, during the fifth injection in 2000. 
POST3 MOISTURE CONTENT CHANGES

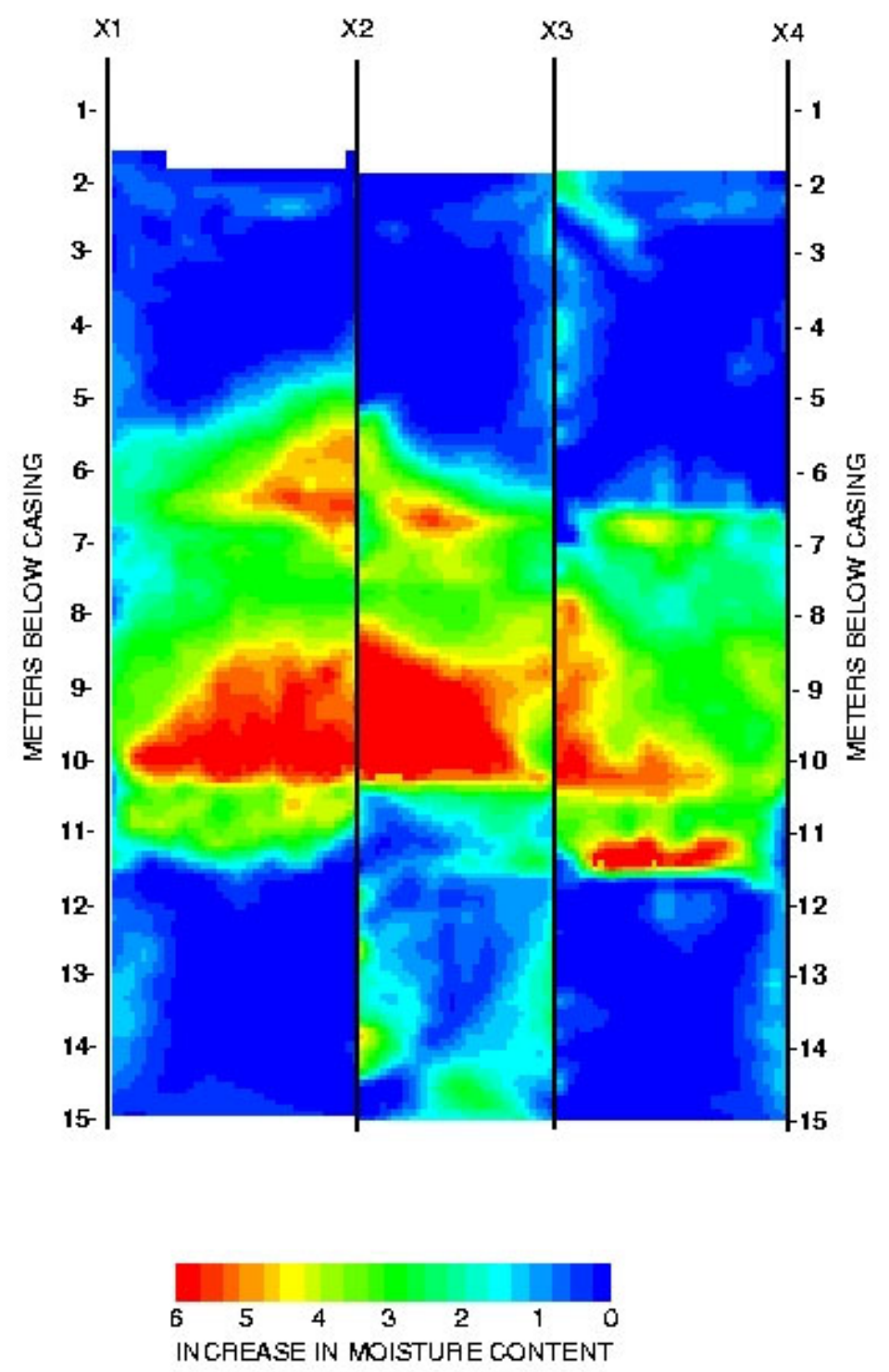

FIGURE 9

Figure 9 Change in water content two weeks after the fifth injection in 2000. 
Figure 10 shows the residual water content in the formation after all of the 2000 injections were completed. As can be seen there was no residual water content beneath 11.5 meters. This is the bottom of the fine grain layer. This agrees with the isotopic tracer work carried out by Lawrence Berkeley National Laboratory (LBNL) in that no tracers were detected below this layer also (pers comm, Mark Conrad, LBNL).

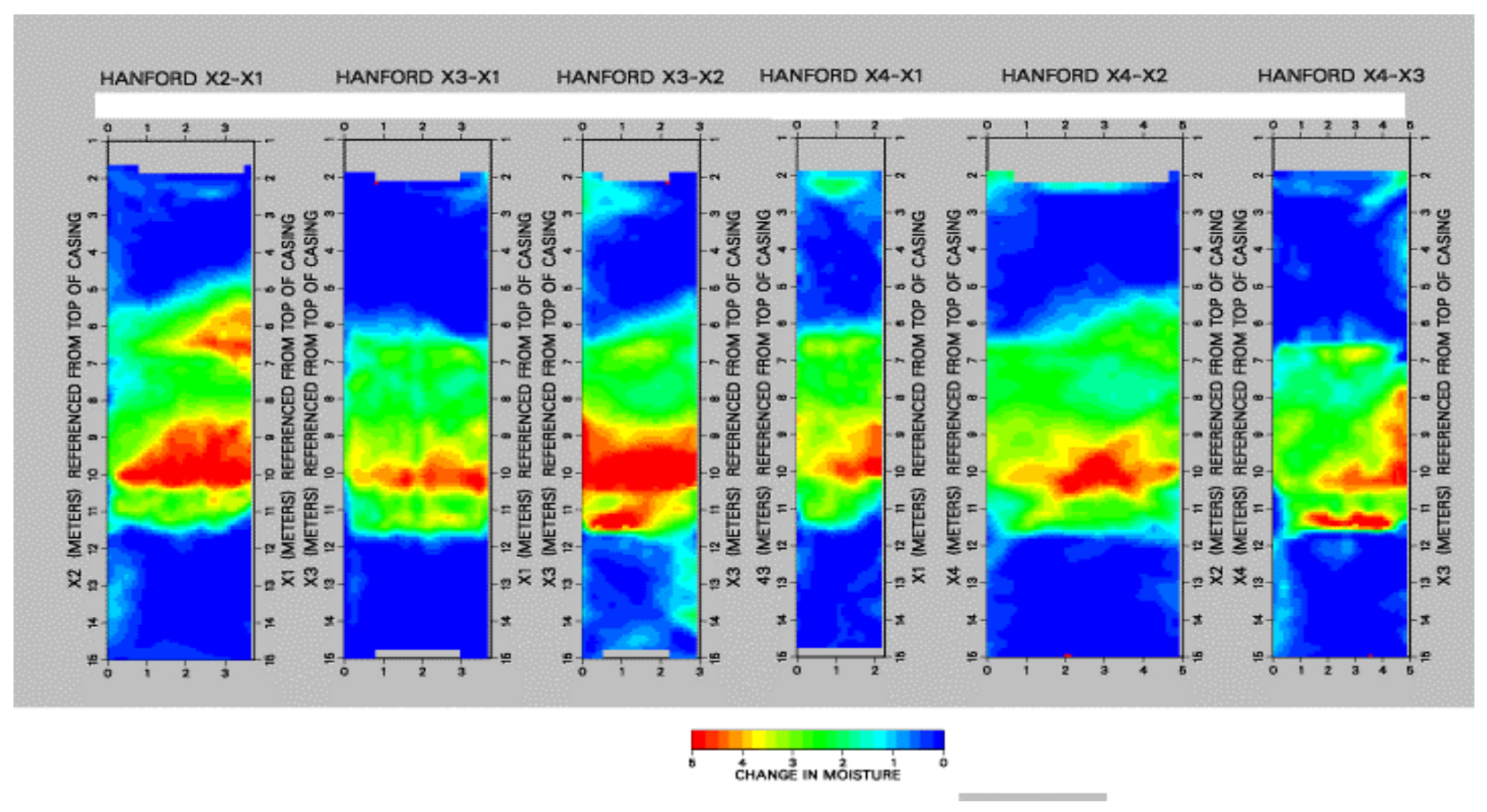

Figure 10 The residual water content a few weeks after the completion of the 2000 Columbia River water injections.

\section{The 2001 Injections}

The 2001 injections were designed to be very similar to the 2000 injections, but with a denser solution. The hydrogeologists hypothosized that the denser more viscous solution $\mathrm{s}$ may not have the same flow characteristics as the river water used in 2000. The same approach and wells were used by the crosswell methods to determine if the fluids did behave differently. Figure 11 shows the radar velocity change between the initial survey in 2000 (the background survey before any water was injected in 2000) and the initial survey in 2001. 

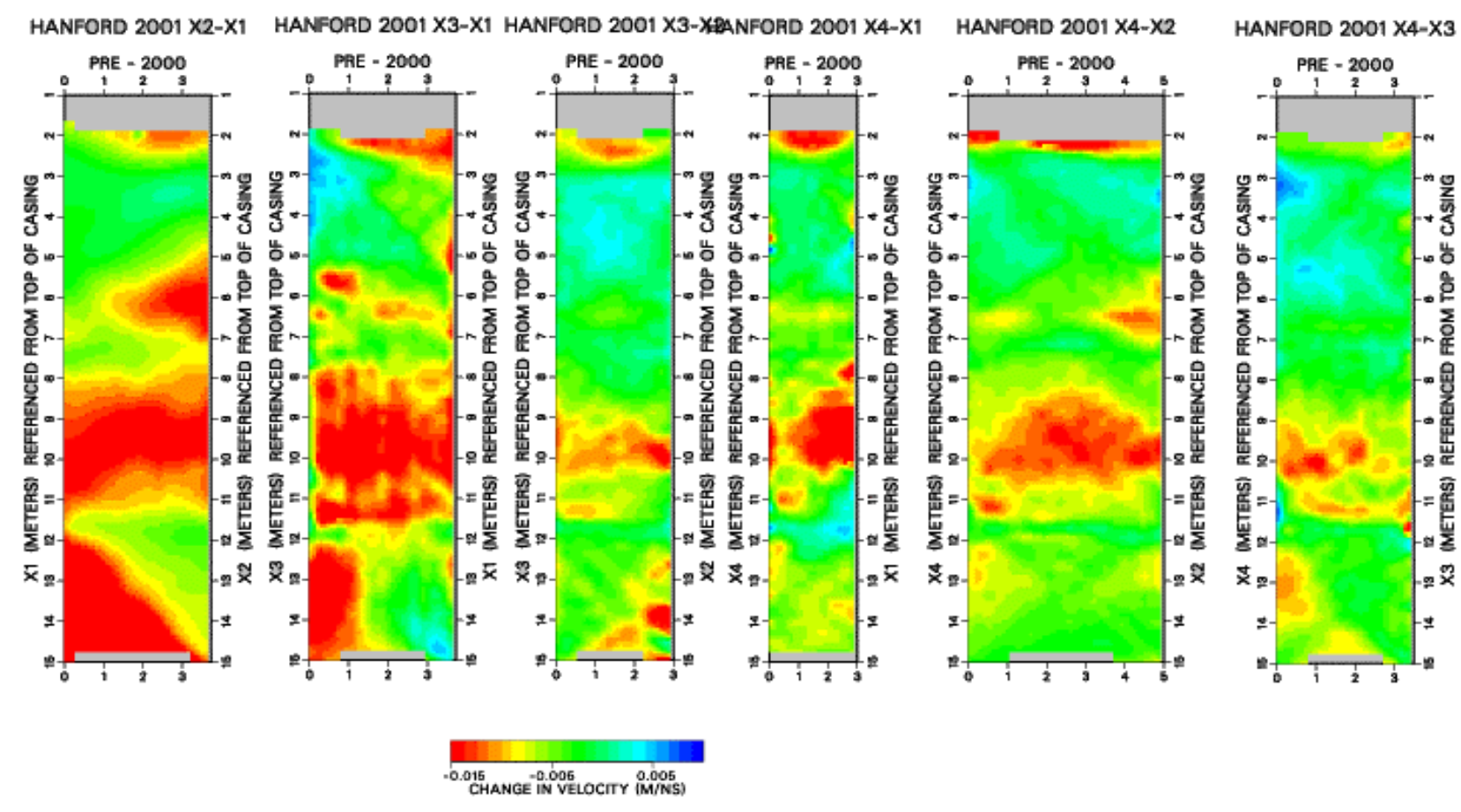

JOHN E. PETERSON

Figure 11 The difference in radar velocity between the 2000 and 2001 background surveys.

This is a measure of how much extra moisture remained in the formation at the time just before the 2001 experiment, presumably due to the 2000 release. It should be noted that the negative change (red in figure 11) below the 11.5 meter depth is real but exagerated. This indicated that some moisture did eventually migrate below the 11.5 meter depth, mainly only near X2 and X3. This moisture may have been introduced when the X holes were filled with water for the seismic survey, the holes did leak, but there was no way of knowing where the leaks were.

The radar work was done slightly different in 2001 than in 2000. In 2001 we wanted to obtain a time lapse meassurement as soon as possible to determine if the heavier sodium thiosulfate was flowing in the same manner as the river water in 2000. There was also a hypothesis that the sodium thiosulfate would be affected by the moisture (or residual water content) in the ground. Figure 12 is a time lapse radar image of the change in radar velocity between wells X1 and X2 after 170, 420 and 500 gallons of sodium thiosulfate was injected. Compare the spatial distribution of these results in Figure 12 to the moisture content change shown in Figure 8. 


\section{Initial Release (2001), sodium thiosulfate: \\ X1-X2: $\quad$ P1 - after 170gal \\ P2 - after $\sim$ 420gal \\ P3 - after 500gal}

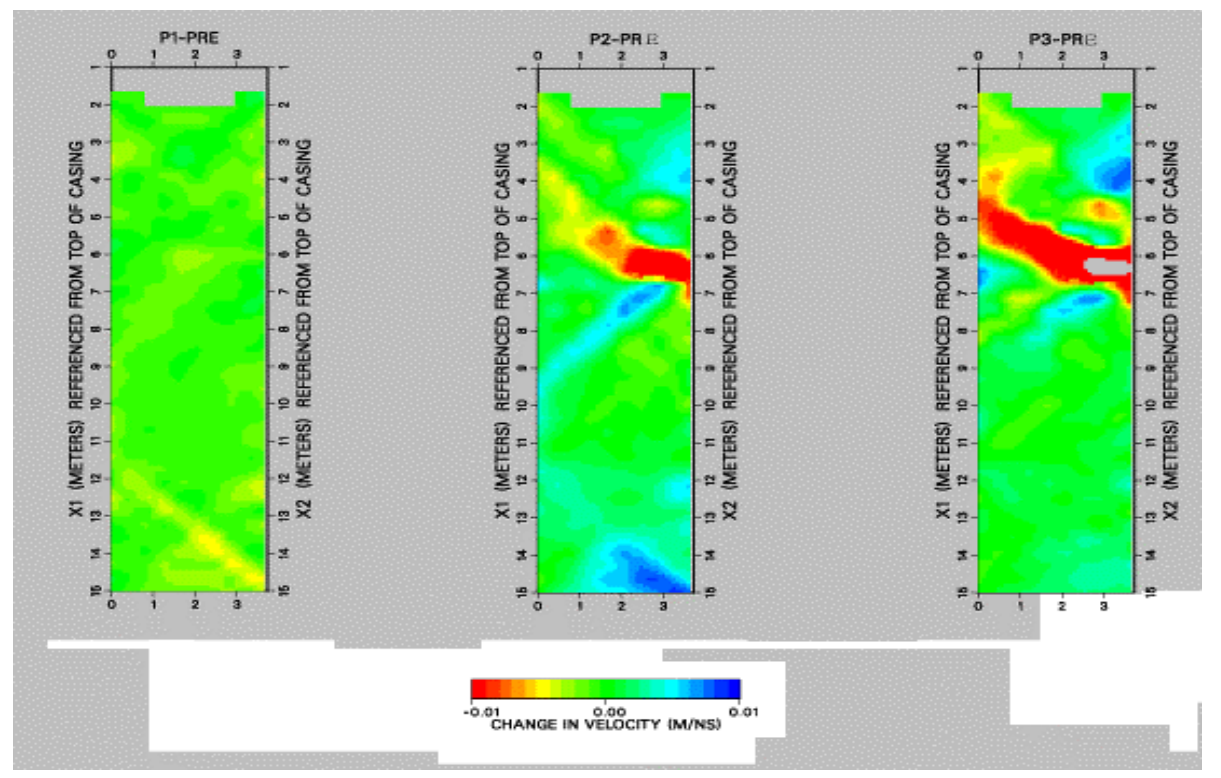

Figure 12 Time lapse images of change in radar velocity between wells X1 and X2 during the initial release of sodium thiosulfate in 2001

It should be noted that the injection was at 5 meters depth about $1 / 2$ meter behind the plane of $\mathrm{X} 1$ to X2 at about one meter from well X2 ( same place as 2000). Figure 13 shows the results of 2000 and 2001 side by side after 500 gallons for each. As can be seen the two are quite different. In 2000 the river water appears to have gone straight down to the boundary of the fine scale layer, then traveled across the layer in a horizontal manner. In 2001 it seems that the more viscous sodium thiosulfate did not go straight down but traved horizontally towards $\mathrm{X} 1$, then sinking to the layer below and then going down gradient ( perpendicular to the plane of X1 and X2). 

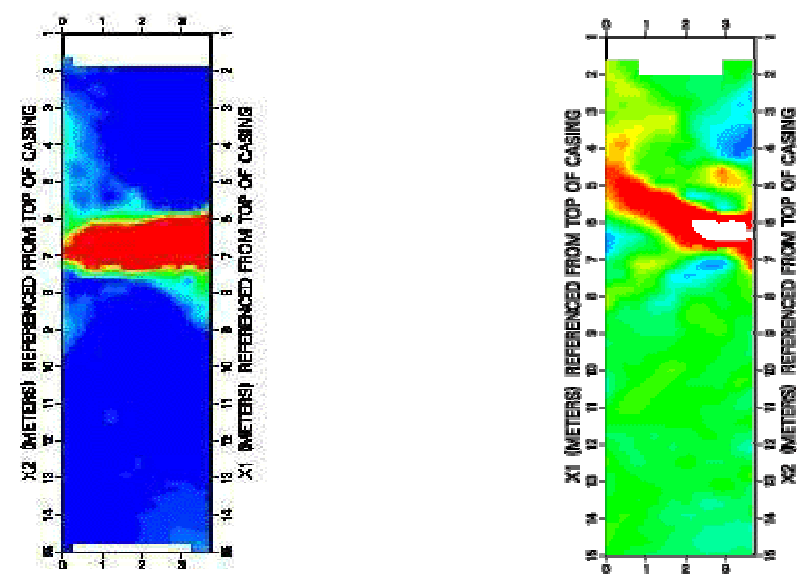

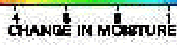

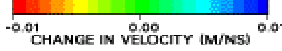

\section{Comparison of 2000-01 data for X1-X2 ( 500gal):}

Figure 12 A side by side comparison of the 2000 and 2001 data. The injection point was about $1 / 2$ meter behide the image plane at 5 meters depth and 1 meter from well X2.

The results of the later monitoring of the 2001 injections are shown in Figures 13 and 14. As can be seen the images are not as detailed as the 2000 images in the center of the images.

This is because of the very conductive sodium thiosulfate. The gray areas are zones in which the signal was attenuated so strongly that we could not detremine the velocity (not pickable). The colors (red to green) have the same meaning as before, i.e., red is more fluid content than the baseline (2001), and green being no change from the baseline. Figure 13 are the data from the radar imaging after all of the sodium thiosulfate was injected. As in the case of the 2000 injection it appears that there was no residual fluid below the 11.5 meter level, at least at the time of the radar survey, which was 2 days after the stopping of the injection of the sodium thiosulfate. Figure 14 however is data that was recorded 9 days after the last injection sequence of fluid. This last sequence was 1000 gallons of water that was used to clean out the tank holding the sodium thiosulfate ( over 5 hours on May 2, 2001) followed by 1000 gallons 


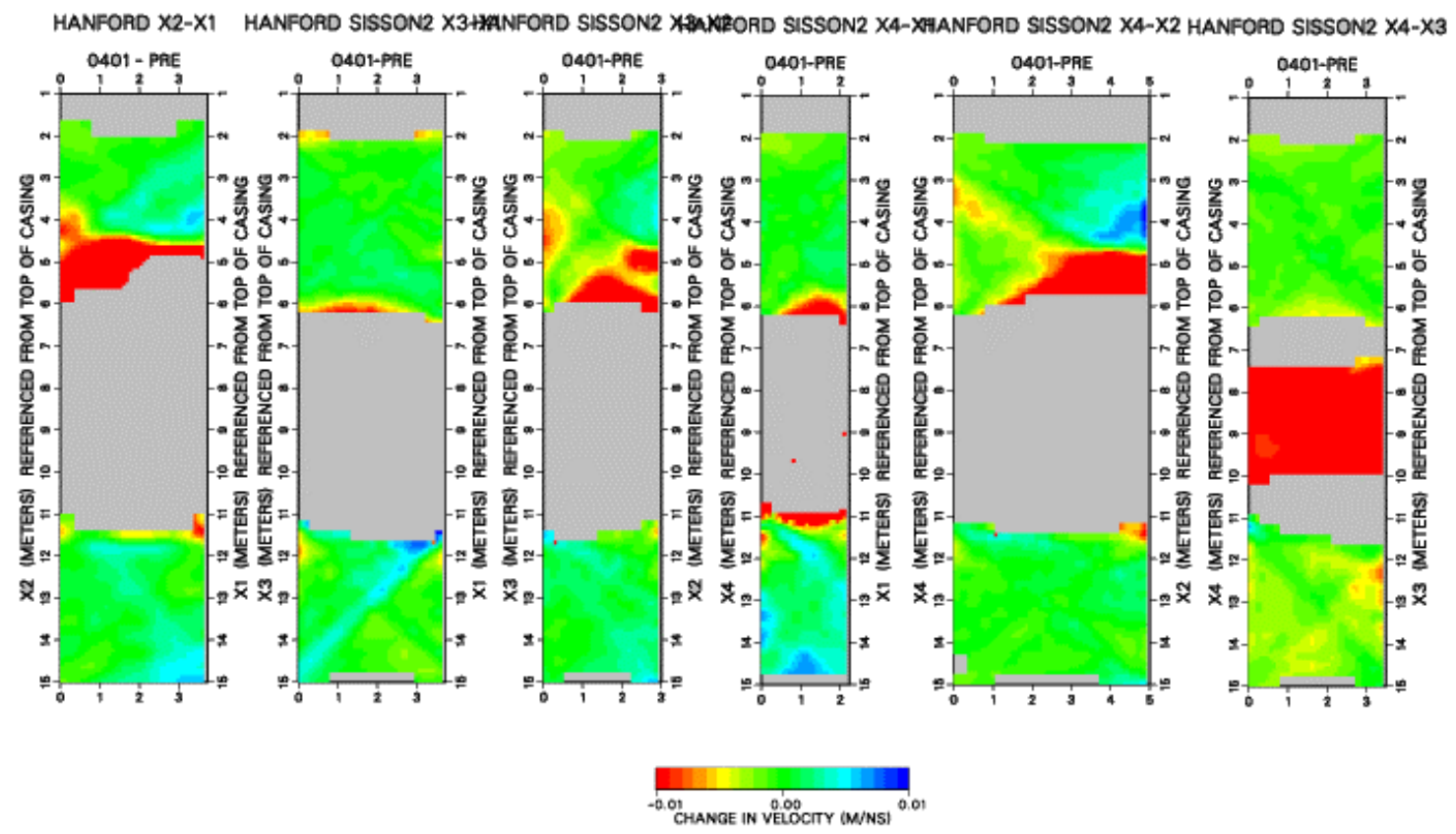

Figure 13 Change in radar velocities from the baseline (2001) between all well pairs after the injection of all of the sodium thiosulfate.

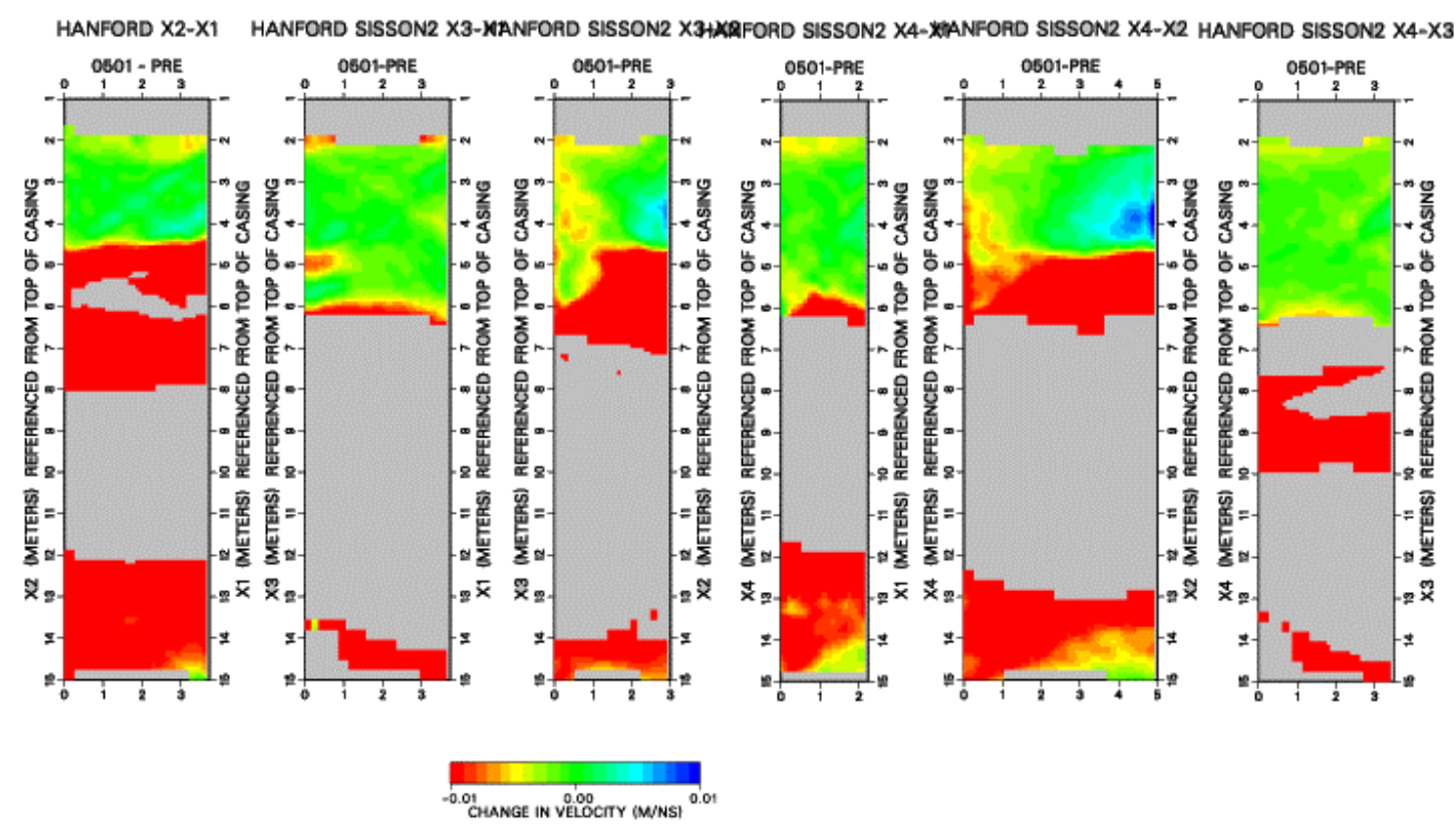

Figure 14 Change in radar velocities from the baseline (2001) between all well pairs nine days after the injection of all of the fluids (sodium thiosulfate plus the follow-on river water injections. 
of river water on May 3 and another 1000 gallons of river water on May 9,2001, for a total of 3000 gallons. Overall 8030 gallons of fluid were injected in 2001. Figure 14 shows that at nine days after the last injection fluid is now getting deeper than the 11.5 meter layer.

\section{Seismic Results}

Seismic data were collected in both 2000 and 2001. Seismic data gives a completely independent measure of the physical properties compared to the electrical and radar methods. Both high frequency ( 2 to 3 kilohertz) and lower frequency ( several hundred hertz) data were collected. The results to date are very surprising in their high quality, for both the close spacing X wells and the long offset work. In 2000 data were acquired from the X1-X4 borehole pair and was processed with the travel times being inverted for the seismic velocity structure. The same algorithm and parameters were used for this inversion of seismic data as were used for the radar data. Figure 15 shows the comparison of the radar and the seismic data estimates of the structure. 
RADAR

HANFORD $\times 4-X 1$

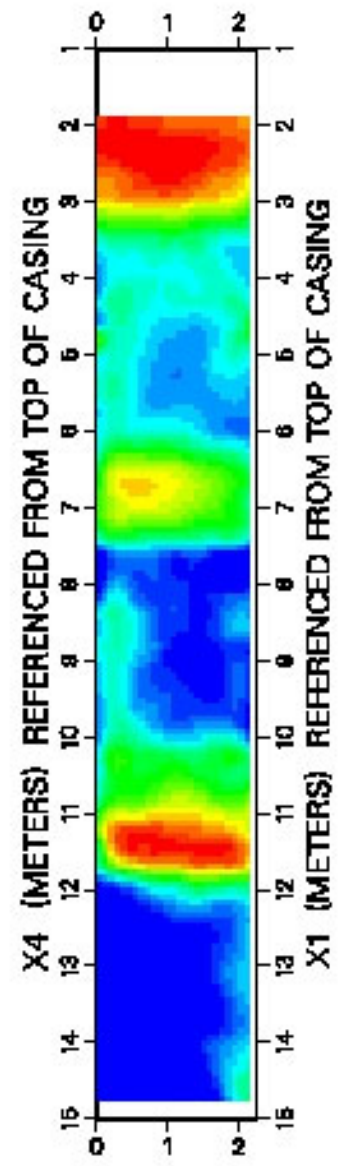

SEISMIC

\section{HANFORD $\times 1-X 4$}

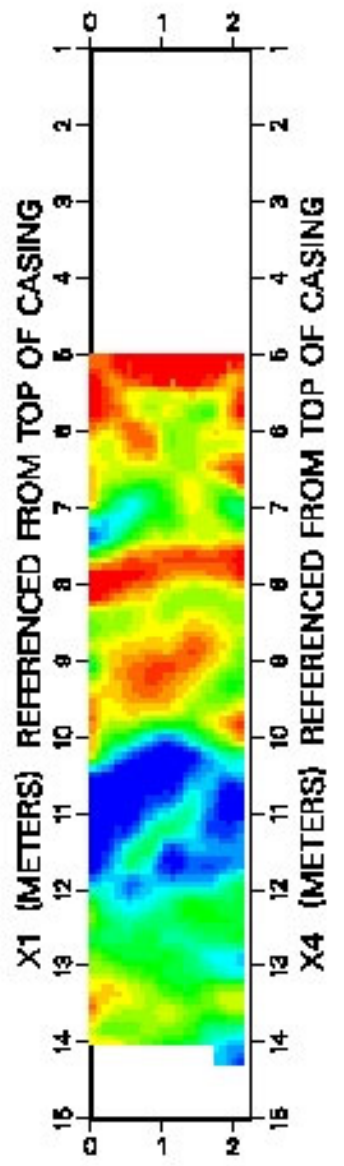

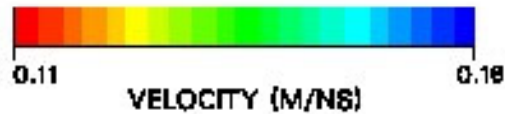

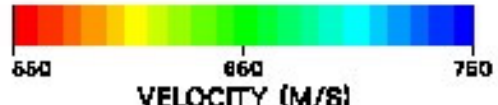

Figure 15 The definition of structure from radar and seismic, note the greater detail in structure derived from the seismic. 
Note that the seismic velocities are quite low, just above the velocity of air. The seismic velocities resolve the same stratigraphy as the radar velocity estimates, however, the high radar velocity layers coincide with the low seismic velocity layers and visa versa. This is most likely due to the fact that electromagnetic wave velocities are high in air, while the acoustic wave velocities are low in air. Therefore, in unsaturated material, the seismic waves should travel slowest in high porosity material, and electromagnetic waves should travel fastest in high porosity material. The velocity tomograms in Figure 15 appear to support this interpretation.

Figures 16 and 17 are data from the long offset $(19 \mathrm{~m})$ seismic test. Instead of the very high frequency piezoelectric seismic source used for the short offset tomography, an intermediate frequency source, known as an orbital vibrator, was used. These data are quite surprising in that sesimic data of such relatively high frequency can be propagated so far in this vadose zone environment. Figure 16 shows good energy up to 300 hertz. Figure 17 is a composit of the different levels showing good P-wave and S-wave energy. This is very encouraging for future imaging at the tank scale.

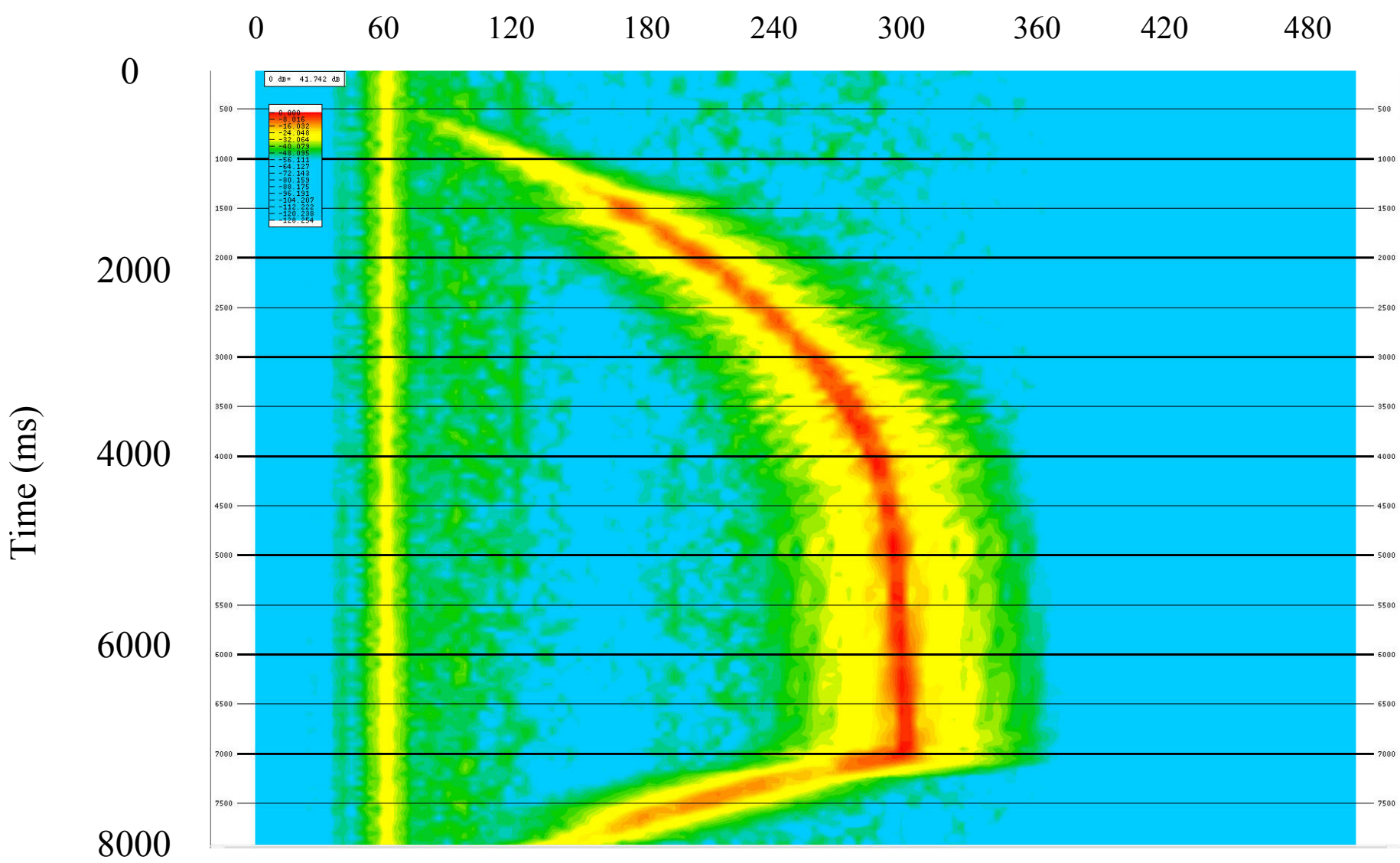

Figure 16 The frequency response as a function of time for the orbital vibrator seismic source, as recorded by hydrophones in the long offset $(19 \mathrm{~m})$ seismic test. Good signal-to- 
noise ratio (over $48 \mathrm{~dB}$ from red to blue) is observed over the source sweep (about 70 to 300 $\mathrm{Hz}$ and then back). The vertical line at $60 \mathrm{~Hz}$ is power line noise.

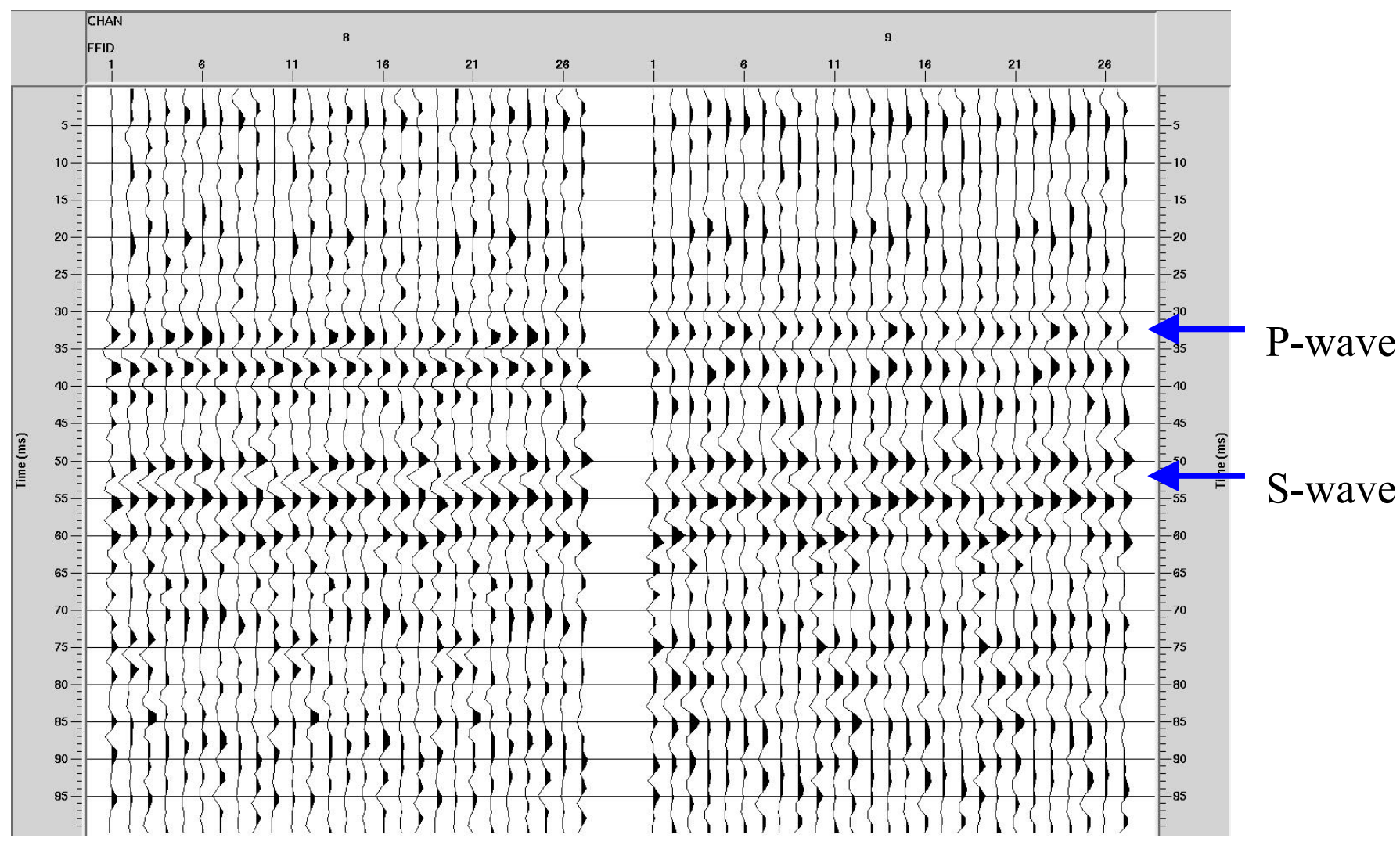

Figure 17 Example of long offset seismic data test at 19 meters through the upper vadose zone using a orbital seismic source in the range of 70 to 300 hertz. The data shown are a series of individual sweeps for two sensors at about 4 and $4.5 \mathrm{~m}$ depth. While tomography was not attempted at this long offset, both P- and S-waves are observed.

In 2001 repeat seismic measurements were made at the site after all of the fluids were injected. The seismic measurements were made on July 17, 2001, almost two months after the final injection. This was necessary to avoid introducing water into the formation from the $\mathrm{X}$-holes which had to be filled to allow seismic coupling of the source( piezoelectric) and receivers (hydrophones). Complete crosswell coverage was obtained between wells X1-X2, $\mathrm{X} 1-\mathrm{X} 3$, and X2-X3.

Shown in Figure 18, 19 and 20 are the tomograms from three different cross sections. These show that the high velocity is below the 10 to 11 meter zone , compare this to the zone in which the radar was highly attenuated (Figure 14). Assuming that the tighter sediments are higher velocity (lower in porosity) then this is consistent. At two months after injection it 
is doubtful that fluid retention is affecting the seismic data, it is assumed that at this point structure is the controlling the seismic velocity. All three cross sections are consistent in that manner.
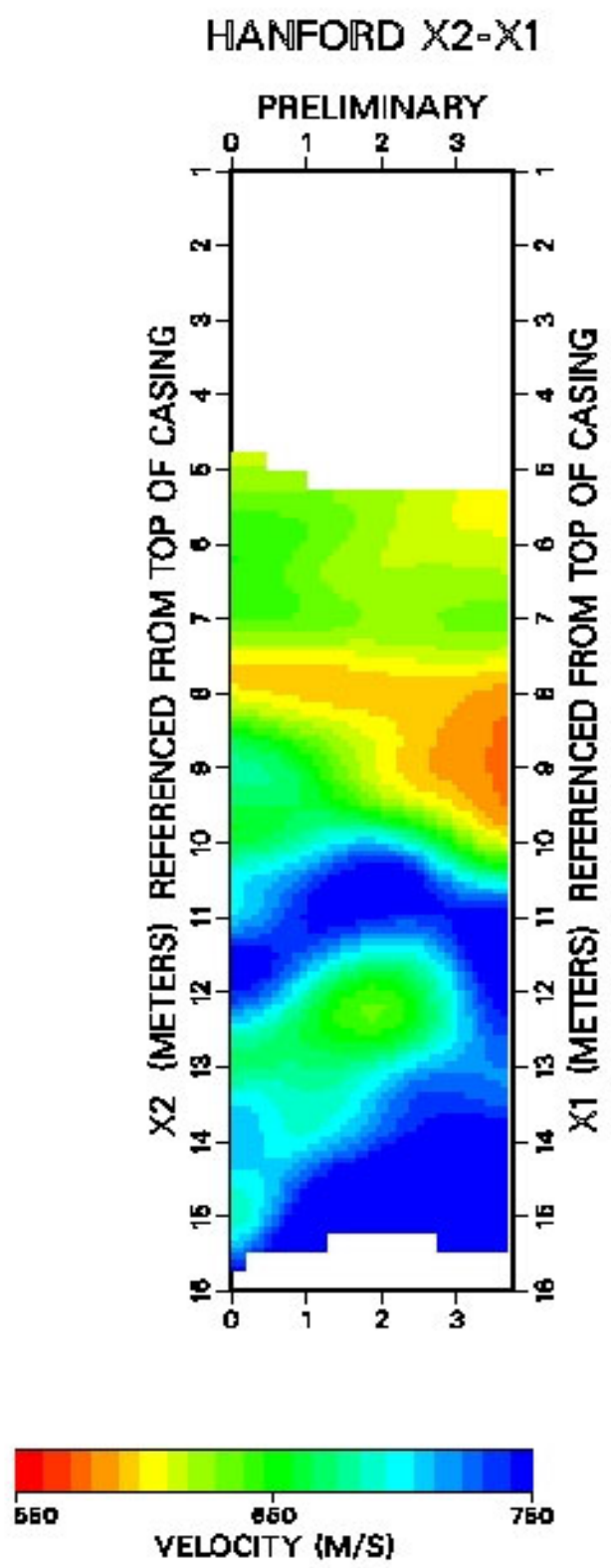

JOHN E. PETERSON

Figure 18. Seismic cross section $X 2$ to $X 1$, Compare to figure 14 , the radar data, the higher velocities correspond to the less permeable sediments 
HANFORD $\times 3 \times \times 1$
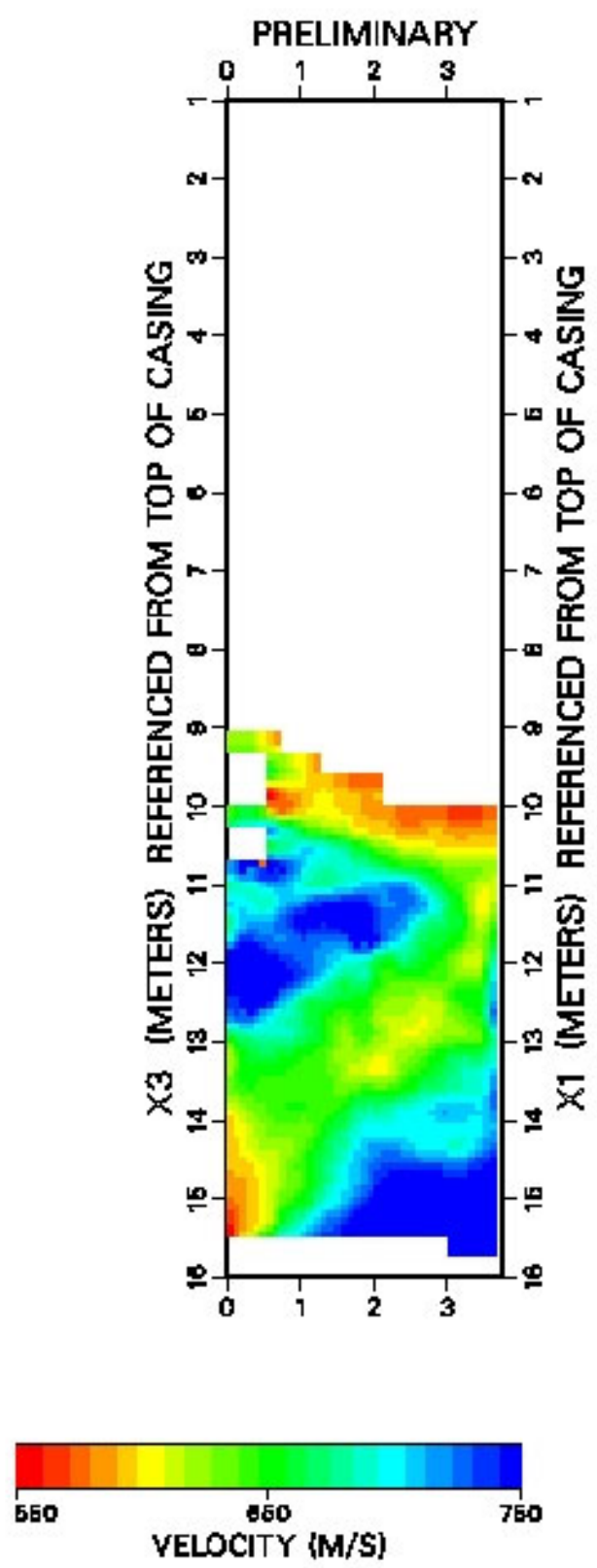

JOHN E. PETER8ON

Figure 19. Seismic cross section $X 3$ to $X 1$, Compare to figure 14 , the radar data, the higher velocities correspond to the tighter sediments 
HANFORD $\times 3 \times \times 2$
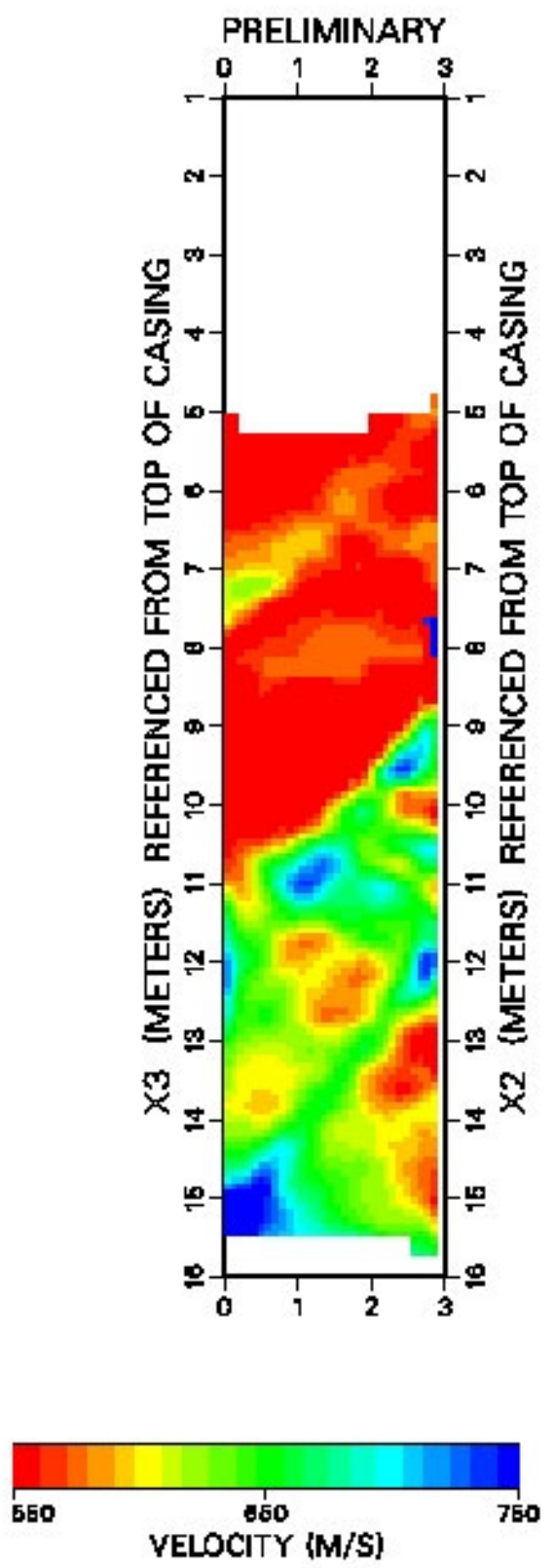

JOHN E. PETERSON

Figure 20. Seismic cross section $\mathrm{X} 3$ to $\mathrm{X} 2$, Compare to Figure 14 , the radar data, the higher velocities correspond to the tighter sediments 


\section{Summary and Conclusions}

Overall the radar and seismic results were excellent. At the time of design of the experiments we did not know how well these two methods could penetrate or resolve the moisture content and structure. It appears that the radar could easily go up to 5, even 10 meters between boreholes at $200 \mathrm{Mhz}$ and even father (up to 20 to $40 \mathrm{~m}$ ) at $50 \mathrm{Mhz}$. The seismic results indicate that at several hundred hertz propagation of 20 to 30 meters giving high resolution is possible. One of the most important results, however is that together the seismic and radar are complementary in their properties estimation. The radar being primarily sensitive to changes in moisture content, and the seismic being primarily sensitive to porosity. Taken in a time lapse sense the radar can show the moisture content changes to a high resolution, with the seismic showing high resolution lithology. The significant results for each method are:

Radar: Delineated geological layers 0.25 to 3.5 meters thick with $0.25 \mathrm{~m}$ resolution.

Delineated moisture movement and content with $0.25 \mathrm{~m}$ resolution.

Compared favorably with neutron probe measurements.

Penetration up to $30 \mathrm{~m}$.

Radar results indicate that the transport of the riverwater is different from that of the heavier and more viscous sodium thiosulfate. It appears that the heavier fluids are not mixing readily with the in-situ fluids and the transport may be influenced by them.

Seismic: Delineated lithology at $.25 \mathrm{~m}$ resolution

Penetration over 20 meters, with a possibility of up to 30 or more meters

Maps porosity and density differences of the sediments

Overall the seismic is mapping the porosity and density distribution. The results are consistent with the flow field mapped by the radar, there is a change in flow properties at the 10 to 11 meter depth in the flow cell. There also appears to be break through by looking at the radar data with the denser sodium thiosulfate finally penetrating the barrier, but not the river water. The radar and seismic data imply that the fluid property differences (density, viscosity, surface tension) between the river water and the sodium thiosulfate do make a difference in flow characteristics. 


\section{REFERENCES}

Freeman-Pollard, J. R., J. A. Caggiano, S. J. Trent and ENSERCH 1994, Engineering evaluation of the GAO-RCED-89-157, tank 241-T-106 vadose zone investigation, BHI00061, Bechtel Hanford, Inc., Richland, Washington.

Peterson, J.E., Paulsson, B.N.P., and McEvilly, T.V., 1985, Application of algebraic reconstruction techniques to crosshole seismic data: Geophysics, 50, 1566-1580.

Raymond, J. R. and E. G. Shdo, 1966, Characterization of subsurface contamination in the SX tank farm. BNWL-CC-701, Pacific Northwest Laboratory, Richland, Washington.

Topp, G.C., J.L. Davis. And A.P. Annan, 1980, Electromagnetic determination of soil water content: Measurements in coaxial transmission lines, Water Resour. Res., 16, 574-582. 